\title{
Scale-dependent detection of the effects of harvesting a marine fish population
}

\author{
Valerio Bartolino ${ }^{1,2, *}$, Lorenzo Ciannelli ${ }^{3}$, Paul Spencer ${ }^{4}$, Thomas K. Wilderbuer ${ }^{4}$, \\ Kung-Sik Chan ${ }^{5}$
}

\author{
${ }^{1}$ Marine Research Institute, Department of Aquatic Resources, Swedish University of Agricultural Sciences, \\ Lysekil 45321, Sweden \\ ${ }^{2}$ Regional Climate Group, Department of Earth Sciences, University of Gothenburg, 40530 Gothenburg, Sweden \\ ${ }^{3}$ College of Oceanic and Atmospheric Sciences, Oregon State University, Corvallis, Oregon 97331, USA \\ ${ }^{4}$ Alaska Fisheries Science Center, NOAA, Seattle, Washington 98115, USA \\ ${ }^{5}$ Department of Statistics and Actuarial Science, University of Iowa, Iowa City, Iowa 52242, USA
}

\begin{abstract}
Certain ecological processes dominate others at particular scales, and the response of populations to exogenous and endogenous forces are typically scale dependent. In spite of this central role played by scale, the temporal and spatial scales of human impacts on ecosystems and populations remain almost unknown. We applied a multiscale regression analysis to investigate the spatiotemporal scales which characterize the fisheries exploitation of yellowfin sole Limanda aspera in the Bering Sea. We found that harvesting affects the abundance of this species simultaneously at local and regional scales. At the local scale harvesting produced a negative effect on local fish densities, particularly in those areas and seasons of high fish aggregation, when both the vulnerability of the fish and the fishing effort increase. At the regional scale harvesting was characterized by a widespread negative effect on the whole fish population. Our findings demonstrate that (1) detection of the fisheries exploitation effects on natural populations is sensitive to the scale of investigation, (2) fisheries harvesting can simultaneously affect multiple ecological scales which are not linearly correlated with each other. We developed analytical techniques for the detection of scale-dependent processes, which can be readily applied to other systems. Our results provide insights on the risks of extrapolating the effects of harvesting on natural populations across scales, making the issues of scale and space central to the management and conservation of natural populations.
\end{abstract}

KEY WORDS: Spatial distribution $\cdot$ Local exploitation $\cdot$ Regional exploitation $\cdot$ Scale $\cdot$ Yellowfin sole $\cdot$ Bering Sea

Resale or republication not permitted without written consent of the publisher

\section{INTRODUCTION}

Ecological processes operate at a range of temporal and spatial scales in both terrestrial and marine ecosystems (Steele 1991, Gardner et al. 2001). For example, North Sea herring Clupea harengus dynamics are affected at multiple scales, as reproduction may depend on specific hydrographic conditions of the spawning areas, larval survival can be increased by fronts as sources of enhanced food supply (Richardson et al. 1986), and juveniles and adults use meso-scale gyres for migration and completing their life cycle (Cushing 1982). In the open ocean the close relationships between physical and biological processes have characteristic time scales that are comparable with the life cycles of the organisms at the different trophic levels (Steele et al. 1994), spanning from a few days for primary producers to decades for large pelagics such as tuna; thus, species differ in their ability to convert 
episodic events into longer-term processes (Schneider 1994).

Whereas the temporal and spatial scales of natural events tend to be positively correlated (Haury et al. 1978), it is unclear how the dynamics of natural populations are affected by human activities across different temporal and spatial scales. Some analyses of human impacts have focused on large-scale patterns affecting habitat loss (Brooks et al. 2002) and decline in marine fish populations from long and intense expoitation (Jackson et al. 2001, Myers \& Worm 2003, 2005, Hutchings \& Reynolds 2004, Reynolds et al. 2005). However, the local effects of removal of fish within a population are less clear on a short temporal scale. Fisheries depletion studies have provided evidence for local effects of exploitation on fish populations but they have generally used indirect measures of abundance such as the decrease in commercial catch rates (Rijnsdorp et al. 2000, Bez et al. 2006), referred to very particular fishing situations such as extremely high exploitation rates (i.e. Eggleston et al. 2003), or are the result of simulations (Maury \& Gascuel 2001). An understanding of how the spatial and temporal scales of exploitation affect population dynamics is required for a fuller understanding of the interaction between fishing activity and marine populations, e.g. whether there is a single scale or several scales at which exploitation of natural populations can be detected.

On a range from small to large scales we can envision 2 types of exploitation processes: local and regional. Local exploitation effect is the hypothesis that intense harvesting pressure may cause detectable small-scale variations on local densities of the target population. Regional exploitation effects refer to general broad-scale reduction over the range of the harvested population as a consequence of previous history of exploitation over longer time scale.

The effects of exploitation are expected to be scale dependent because the response of populations reflects their spatial patchiness, seasonal variability, and dispersal patterns, which are typically scale dependent (Ricklefs 1990, Schneider 1994). Local decline in fish density due to exploitation can affect larger spatial domains over longer time intervals because fish redistribute from outlying areas to the fished area, and the rate at which this redistribution occurs is expected to be proportional to the exploitation intensity and the dispersal rate. In a theoretical case where the dispersal rate was constant between individuals and seasons, local and regional exploitation would be linked via the dispersal rate and perhaps obviate the need for distinguishing between these scales. However, this would not be valid for populations with ontogenetic and sex-specific spatial dynamics, or under the occurrence of seasonal migratory behaviours (i.e. feeding and spawning migrations). Therefore it is expected that abrupt changes in the spatial configuration of a fish population (as for example resulting from local intense harvesting) will have a population-level impact even if it is not detected on a global scale in the short-term.

Because fisheries activities tend to concentrate where fish are more abundant, similar to the aggregative response observed in predator-prey relationships (Charnov 1976, Cook \& Hubbard 1977), a positive relationship between harvesting intensity and resource abundance is often observed. Consequently, detection of fishery-induced local 'gaps' in the fish distribution, revealed by a negative relationship between exploitation and local fish density, may be masked by the fishing pattern. Moreover, the effects of local exploitation can be masked by increased harvesting efficiency and effort which may result from a decline in the abundance of fish (Hilborn \& Walters 1992). For these reasons, analyses of the scale-dependent effects of fishery harvests would ideally be applied to cases with long and spatially extensive fishing patterns with both fishery-dependent and fishery-independent datasets.

The purpose of the present study is to develop an analytical framework suitable for testing the simultaneous effects of fisheries-fish interaction at the multiple spatiotemporal scales at which it may occur, and to apply it to yellowfin sole Limanda aspera in the eastern Bering Sea (EBS). To this end, we adopted a spatially variant formulation that allows detection of spatially heterogeneous effects of harvesting on local population abundances and accounts for the effect of removal of organisms over a variety of temporal and spatial scales. A range of spatiotemporal scales were evaluated, and the scales which provided the best fit to the data were identified.

\section{MATERIALS AND METHODS}

The present study integrates 2 independent pieces of information, survey and commercial catch data, within the same analytical framework. We choose yellowfin sole in the EBS (Fig. 1) because of its strong seasonal habitat associations (McConnaughey \& Smith 2000, Spencer 2008, Bartolino et al. 2011), and the well-documented history of exploitation since the mid 1950s. Before the 1970s, the fishery in the EBS consisted primarily of foreign vessels (i.e. Japan and 


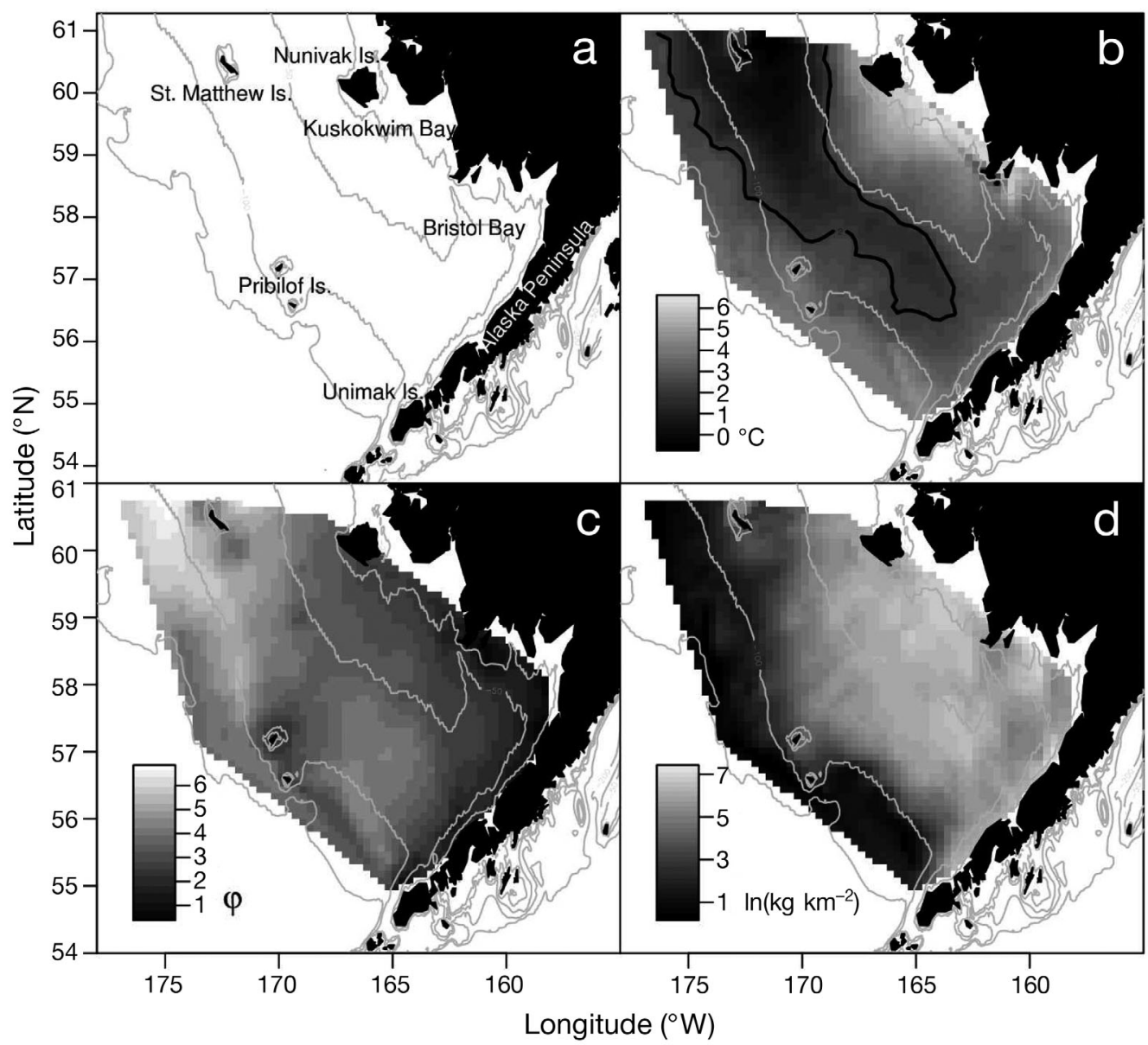

Fig. 1. (a) Eastern Bering Sea shelf showing the 20,50, 100, and $200 \mathrm{~m}$ isobaths (gray lines). (b) Average summer bottom temperature (1982 to 2007) with the $2{ }^{\circ} \mathrm{C}$ isotherm (black line). (c) Sediment size ( $\varphi$ : $-\log _{2}$ [diameter in mm]). (d) Average logtransformed yellowfin sole Limanda aspera density from the groudfish survey (1991 to 2007)

USSR). Since the 1980s, the fishery experienced a major transition and foreign vessels were progressively replaced by a US fishery that from 1991 onwards became the only one harvesting yellowfin sole in the EBS.

\section{Data}

Yellowfin sole data were collected during the annual groundfish survey conducted by the US National Marine Fisheries Service during 1982 to 2007 (Fig. S1 in Supplement 1 at www.int-res.com/articles/ suppl/m444p251_supp.pdf). The sampling design is based on a fixed regular grid of $37 \times 37 \mathrm{~km}$ (study area approximately $450000 \mathrm{~km}^{2}$ ), and systematic sampling occured over a period of 6 to $8 \mathrm{wk}$ during late spring and summer (Stauffer 2004, Lauth \& Acuna 2007). We calculated fish density for each survey sampling location as biomass of fish per swept area $\left(\mathrm{kg} \mathrm{km}^{-2}\right)$.
A number of physical and oceanographic parameters were used as co-located variables in the statistical models (Fig. 1). Bottom depth $(D)$ and temperature $(T)$ were measured directly at the survey stations, whereas sediment size ( $K$, expressed in units of $\varphi$ : $-\log _{2}$ [diameter in $\left.\mathrm{mm}\right]$ ) was estimated at the survey stations by kriging the archived sediment size data in Smith \& McConnaughey (1999). These parameters are important regulators of yellowfin sole distribution (McConnaughey \& Smith 2000, Spencer 2008, Bartolino et al. 2011).

Catch data have been collected by observers on board commercial fishing vessels since the 1970s. For each commercial catch, observers record geographical position (longitude and latitude) and total catch of yellowfin sole, extrapolated from a sample. Sampling effort and its spatial coverage became more consistent with the advent of the national fleet; consequently, only catch data from 1991 to 2008 have been used in our analysis. Total catches recorded by ob- 
servers represented between 51 and $76 \%$ of the officially reported annual total landing of yellowfin sole in the EBS (Wilderbuer et al. 2008) and they were highly correlated $(\mathrm{R}=0.913, \mathrm{p}<0.01)$. Due to the high representativeness and quality of the data collected by the observers, it was possible to use the official annual total landings to scale observer catches to the total amount of yellowfin sole biomass exploited by fisheries in the EBS. A catch variable $(C)$ representing the harvesting effect was calculated as the sum of the commercial catches prior to the survey weighted according to their distance in time and space from each survey point. Weighting was accomplished using a Gaussian kernel on both time and space. The value of the parameter $\sigma$, the scale parameter in our analysis, defines how sharply or smoothly the weight curve decreases moving back in time and across space (see Supplement 2 at www.intres.com/articles/suppl/m444p251_supp.pdf).

\section{Regression models}

The effect of fishery exploitation on yellowfin sole in the EBS was studied with regression models applied to 2 different groups of data: (1) fish density groundfish survey; and (2) commercial trawlers catch per unit effort (CPUE). In both cases the regression analysis was restricted to non-zero hauls in the response variable, and generalized additive models (GAM) were used. The analysis of the groundfish survey data aimed to identify the main scales where the harvesting process occurred. Modeling of commercial trawler CPUE was used for independent validation of the small-scale effects of harvesting and for investigating seasonality of the harvesting process.

For groundfish survey data, a total of 3764 hauls were used to model yellowfin sole fish density over $17 \mathrm{yr}$ (1991 to 2007), with an average of 221 observations per year. Two different models were applied, a spatially invariant and a spatially variant model. In both formulations, the dependent variable $x_{t, y,(\rho, \lambda)}$ is the natural logarithm of yellowfin sole density at a particular location $\rho, \lambda$ (identified by longitude and latitude degrees), time $t$ (day of the year), and year $y$. The spatially invariant model was formulated as follows:

$$
\begin{aligned}
x_{t, y,(\rho, \lambda)}= & a_{Y}+g_{1}(t)+g_{2}\left(T_{t, Y,(\rho, \lambda)}\right)+g_{3}\left(K_{(\rho, \lambda)}\right)+ \\
& g_{4}\left(C_{t, Y,(\rho, \lambda)}^{\prime}\right)+g_{5}\left(C_{t, y,(\rho, \lambda)}^{\prime \prime}\right)+s_{1}(\rho, \lambda)+e_{t, Y,(\rho, \lambda)}
\end{aligned}
$$

where $g$ and $s_{1}$ are 1-dimensional (Wood 2004) and 2dimensional (Wood 2003) smoothing functions respectively, $a$ is the year-specific intercept, $C^{\prime}$ and $C$ " are log-transformed sum of weighted commercial catches at a small and large scale, respectively, and $e_{t, y,(\rho, \lambda)}$ is a normally distributed error term. This formulation assumes that the effect of the catch and environmental variables are invariant over the entire range of yellowfin sole distribution. For testing a variable spatial effect of fisheries catches, we used a locally variable coefficient model (Hastie \& Tibshirani 1993), the spatially variant formulation, expressed as follows:

$$
\begin{aligned}
x_{t, y,(\rho, \lambda)}= & a_{Y}+\alpha_{1} C_{t, Y,(\rho, \lambda)}^{\prime}+\alpha_{2} C_{t, Y,(\rho, \lambda)}^{\prime \prime}+g_{1}(t)+ \\
& g_{2}\left(T_{t, Y,(\rho, \lambda)}\right)+g_{3}\left(K_{(\rho, \lambda)}\right)+s_{1}(\rho, \lambda)+ \\
& s_{2}(\rho, \lambda) C_{t, Y,(\rho, \lambda)}^{\prime}+s_{3}(\rho, \lambda) C_{t, Y,(\rho, \lambda)}^{\prime \prime}+e_{t, Y,(\rho, \lambda)}
\end{aligned}
$$

where $\alpha_{1}$ and $\alpha_{2}$ are the slopes of the average effects of commercial catch throughout the region, while $s_{2}$ and $s_{3}$ are 2-dimensional smoothing functions that describe the spatial variation in these effects. This specific formulation allows us to disentangle 2 contrasting underlying processes. Namely, fisheries catch are expected to be positively related to the availability of fish (parametric coefficient $\alpha$ ), especially at a small scale, but at the same time high levels of exploitation are expected to produce local decline on local fish densities (2-dimensional smoothing function $s$ ).

The models for commercial trawler CPUEs were fitted on a much larger number of observations (169 284 data points) than for groundfish surveys, collected over a period of $18 \mathrm{yr}$ (1991 to 2008). The response variable CPUE $\mathrm{E}_{t, y_{(}(p, \lambda)}$ is the natural logarithm of the standardized yellowfin sole trawl fleet catch $\left(\mathrm{kg} \mathrm{min}{ }^{-1}\right)$ at a particular location $\rho, \lambda$ (identified by longitude and latitude degrees), time $t$ (day of the year), and year $y$.

In addition to a spatially-invariant and a spatiallyvariant formulation (Table 1), we also tested a temporally variable spatial effect of harvesting, according to the marked seasonality observed in the yellowfin sole catches (see 'Results' and Fig. 3). The following model was built:

$$
\begin{aligned}
& \text { CPUE }_{t, y,(\rho, \lambda)}=a_{y}+g_{1}(t)+ \\
& \begin{cases}s_{1}(\rho, \lambda)+\alpha_{1} C_{t, y,(\rho, \lambda)}^{\prime}+s_{2}(\rho, \lambda) C_{t, y,(\rho, \lambda)}^{\prime}+e_{t, y,(\rho, \lambda)} & \text { Period } 1 \\
s_{3}(\rho, \lambda)+\alpha_{2} C_{t, y,(\rho, \lambda)}^{\prime}+s_{4}(\rho, \lambda) C_{t, y,(\rho, \lambda)}^{\prime}+e_{t, y,(\rho, \lambda)} & \text { Period 2 } \\
s_{5}(\rho, \lambda)+\alpha_{3} C_{t, y,(\rho, \lambda)}^{\prime}+s_{6}(\rho, \lambda) C_{t, y,(\rho, \lambda)}^{\prime}+e_{t, y,(\rho, \lambda)} & \text { Period } 3 \\
s_{7}(\rho, \lambda)+\alpha_{4} C_{t, y,(\rho, \lambda)}^{\prime}+s_{8}(\rho, \lambda) C_{t, y,(\rho, \lambda)}^{\prime}+e_{t, y,(\rho, \lambda)} & \text { Period 4 }\end{cases}
\end{aligned}
$$

where $C^{\prime}$ is the logarithm of the sum of commercial catches at the same optimal small scale identified for the model on the groundfish survey data (see 'Multiscale analysis'). The residuals of this model did not 
Table 1. Spatially invariant (Models 1 and 3) and spatially variant (Models 2, 4 and 5) models of yellowfin sole density $x_{t, y,(\rho, \lambda)}$ and abundance $\mathrm{CPUE}_{t, y,(p, \lambda)}$ estimated from groundfish survey (1991 to 2007) and commercial fisheries catch data (1991 to 2008) in the eastern Bering Sea. Deviance explained (\%) and generalized cross validation (GCV) scores are included. Sample size is 3764 for the groundfish survey density and 169284 for the fisheries catch abundance. $a$ : intercept; $g$ and $s: 1-$ and 2dimensional smoothing functions, respectively; $t$ : day of the year; $y$ : year; $T$ : bottom temperature; $K$ : sediment size; $C$ : logtransformed sum of weighted commercial catches; $\alpha$ : slope function; $(\rho, \lambda)$ : long./lat. co-ordinates; e: error term

\begin{tabular}{|c|c|c|c|}
\hline Model & Formulation & Dev. expl. $(\%)$ & GCV \\
\hline 1 & $x_{t, y,(\rho, \lambda)}=a_{y}+g_{1}(t)+g_{2}\left(T_{t, y,(\rho, \lambda)}\right)+g_{3}\left(K_{(\rho, \lambda)}\right)+g_{4}\left(C_{t, y,(\rho, \lambda)}^{\prime}\right)+g_{5}\left(C^{\prime \prime}{ }_{t, y,(\rho, \lambda)}\right)+s_{1}(\rho, \lambda)+e_{t, y,(\rho, \lambda)}$ & 73.4 & 0.96 \\
\hline 2 & $\begin{aligned} x_{t, y,(\rho, \lambda)}= & a_{Y}+\alpha_{1} C_{t, y,(\rho, \lambda)}^{\prime}+\alpha_{2} C^{\prime \prime}{ }_{t, y,(\rho, \lambda)}+g_{1}(t)+g_{2}\left(T_{t, y_{,}(\rho, \lambda)}\right)+g_{3}\left(K_{(\rho, \lambda)}\right)+s_{1}(\rho, \lambda)+ \\
& +s_{2}(\rho, \lambda) C_{t, y,(\rho, \lambda)}^{\prime}+s_{3}(\rho, \lambda) C^{\prime \prime}{ }_{t, y,(\rho, \lambda)}+e_{t, Y,(\rho, \lambda)}\end{aligned}$ & 76.0 & 0.89 \\
\hline 3 & $\mathrm{CPUE}_{t, y,(\rho, \lambda)}=a_{\mathrm{Y}}+g_{1}(t)+g_{2}\left(C_{t, y,(\rho, \lambda)}\right)+s_{1}(\rho, \lambda)+e_{t, y,(\rho, \lambda)}$ & 69.6 & 1.12 \\
\hline 4 & $\operatorname{CPUE}_{t, y,(\rho, \lambda)}=a_{y}+\alpha_{1} C_{t, y,(\rho, \lambda)}+g_{1}(t)+s_{1}(\rho, \lambda)+s_{2}(\rho, \lambda) C_{t, y,(\rho, \lambda)}+e_{t, y,(\rho, \lambda)}$ & 70.7 & 1.08 \\
\hline 5 & 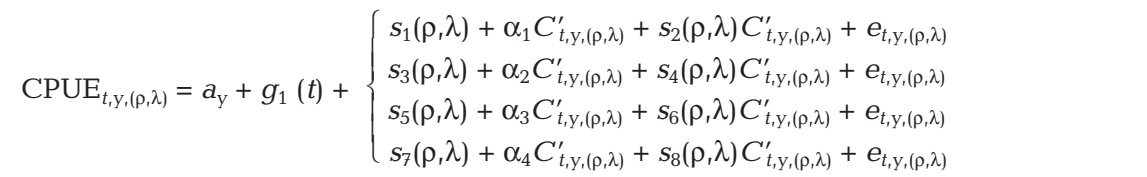 & 73.8 & 0.97 \\
\hline
\end{tabular}

show temporal dependency, but they were spatially correlated. Unbiased estimates of covariate p-values were obtained with a mixed model approach, including a spatial correlation structure (see Supplement 3 at www.int-res.com/articles/suppl/m444p251 _supp.pdf).The regression models were fitted using $\mathrm{R}$ and the library mgcv 1.3-29.

\section{Multiscale analysis}

Our intent was to investigate the scale at which harvest affects local fish density. To this extent we used a statistical model (specifically the model built on the groundfish survey data) that contained a harvest effect at a variety of scales, and then estimated the scale at which the model best reproduced the observed data. We fixed in the model a large-scale harvest effect representative of regional exploitation (Supplement 2), and then we added an additional harvest term at progressively smaller scales. We opted to fix the large-scale effect because adult yellowfin sole exhibit substantial intra-seasonal migrations between the middle and coastal shelf of the EBS for feeding and spawning purposes (Bakkala 1981, Wilderbuer et al. 1992, Nichol 1997, 1998), and because this species has a long and documented history of commercial exploitation (Wilderbuer et al. 2008). The optimal scale for studying the effect of commercial catches on yellowfin sole density was searched via minimizing the generalized cross validation score (GCV) of the model (Wood 2006). Finally, we tested whether the optimal scale so selected was also statistically significant. Our approach was based on a bootstrap aimed at generating a large number of replicates of the small-scale catch variable that were independent from the response variable. A total of 1000 randomly shuffled replicates of the small-scale commercial catch variable were generated and a minimum GCV was searched again across different temporal and spatial scales for all of the replicates. Finally, the reference distribution for the minimum GCV from the bootstrap was compared with the value obtained from the scale analysis on the original data. A GCV value smaller than $5 \%$ of the independently generated distribution would indicate that the optimum identified is significant at this particular spatial and temporal scale.

\section{RESULTS}

Results indicate that species-environment interactions and exploitation processes both have statistically significant effects on the spatial dynamics of yellowfin sole in the EBS. The spatially variant formulation for the groundfish survey indexes of abundance was statistically superior to the spatially invariant formulation both in terms of GCV and deviance explained (Table 1). Inspection of the model residuals did not reveal any major departure from the main assumptions of normality and homogeneity of variance. Predictions of the mean distribution confirmed the general preference of yellowfin sole for the coastal and middle shelf waters. The shape of the effects of day of the year and those of the environmental variables were consistent between the 2 formulations (Fig. 2 and Supplement 4 at www.int-res.com/articles/ 

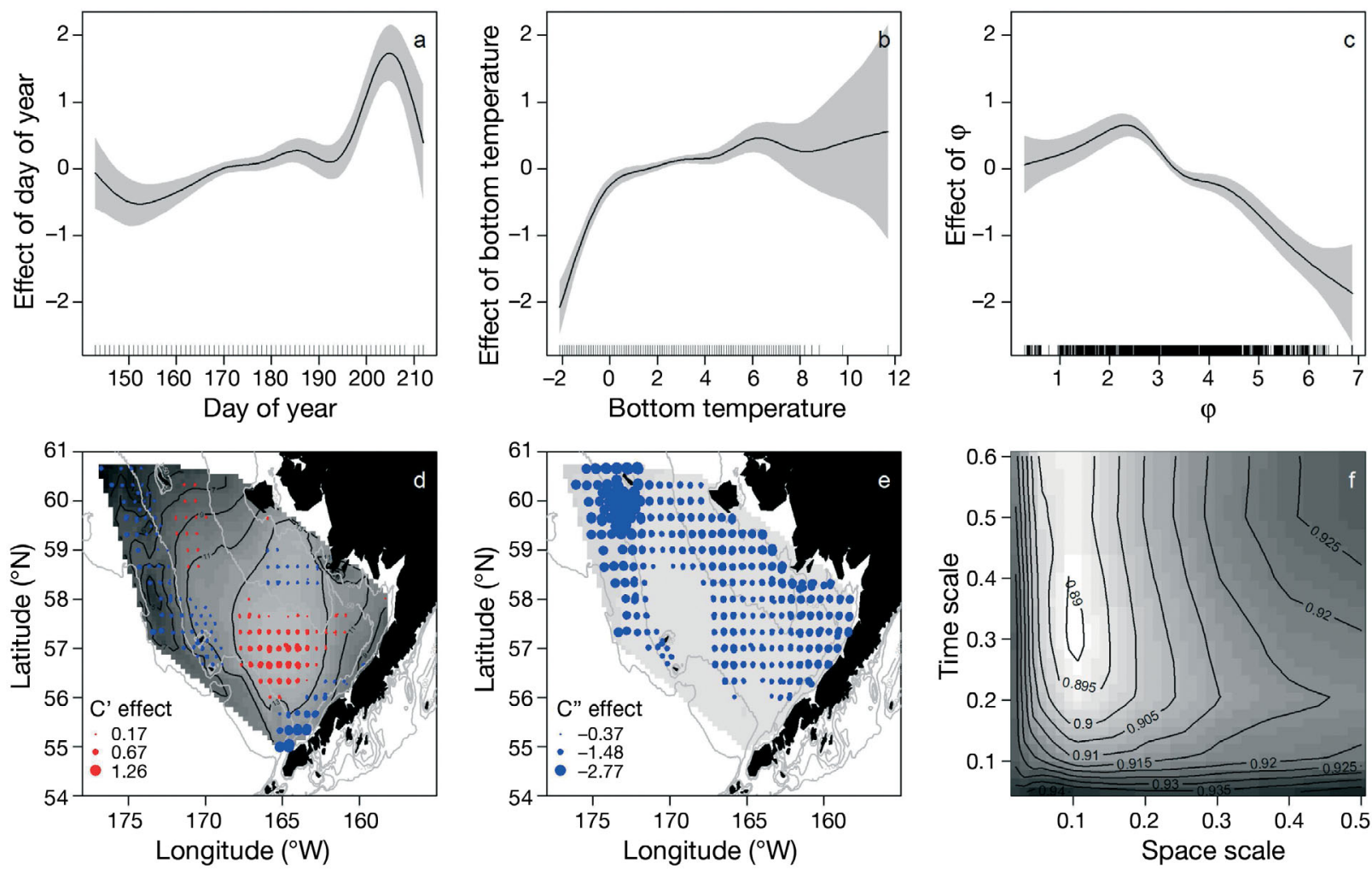

Fig. 2. Effects of spatially invariant terms on yellowfin sole local density as estimated from Model 2 (see Table 1), with the shaded regions indicating $95 \%$ confidence interval for the variables (a) day of the year, (b) bottom temperature and (c) sediment size $(\varphi)$. Ticks along $x$-axis in (a)-(c) indicate measurement points. Spatial effects of log-transformed fisheries catch (d) at small scale and (e) large scale on yellowfin sole Limanda aspera local density as estimated from Model 2 overlaid with the average value of the catch variable; circle size is proportional to the estimated variation in yellowfin sole density for 1-unit increment in the value of log-transformed fisheries catches at both small and large scale. Red and blue bubbles indicate an increase and decrease, respectively. (f) Generalized cross validation score (GCV) surface from Model 2 as function of the scale ( $\sigma$ ) of the log-transformed fisheries catches

suppl/m444p251_supp.pdf) and the model improvements were attributed to the inclusion of a locally variable effect of the 2 fisheries catch variables. The small- and large-scale effects of commercial catches, calculated as the sum of weighted catches occurring before the survey (see Supplement 2), were both statistically significant $\left(C^{\prime}: F=12.5\right.$, equivalent $[\mathrm{e}] \mathrm{df}=$ 29.1, p < 0.001; $C^{\prime \prime}: F=5.8$, edf $\left.=29.5, \mathrm{p}<0.001\right)$. We found that at large scale the effect of fisheries catches was mostly dominated by a parametric coefficient that determined an overall negative effect of fisheries catches across the whole study area. In contrast, at small scale a locally variable effect characterized the relationship between fisheries catch and yellowfin sole local density. This implies that the small-scale effect of harvest significantly changed with location. At this small scale we found large areas of both positive and negative association between fish densities and the amount of fish caught by the fisheries. Areas characterized by a negative effect of catches were observed from the Pribilof Islands and northward along the $150 \mathrm{~m}$ isobath, off the Alaska Peninsula and over the narrow shelf off Unimak Island, and in a welldefined area on the middle shelf of the EBS, between Kuskokwim Bay and Bristol Bay (Fig. 2). The central area and the area off Unimak Island, both represented by local negative slopes, are particularly relevant because some of the highest catches co-occured here (Fig. 2). Main areas of positive association were found in the central part of the middle shelf, and southern St. Matthew Island, between the $50 \mathrm{~m}$ and $100 \mathrm{~m}$ isobaths.

The multiscale analysis of fisheries catch detected a clear and statistically significant $(p<0.01,1000$ bootstrap replicates) optimum in the groundfish survey model performances (i.e. minimum in the GCV score) for a well-defined combination of spatial and temporal scales (Fig. 2f). This optimal spatiotemporal window approximately corresponded to a reduction of $40 \%$ in the influence of the catches within a period of $3 \mathrm{mo}$ and a distance of $180 \mathrm{~km}$ (Supplement 2). 


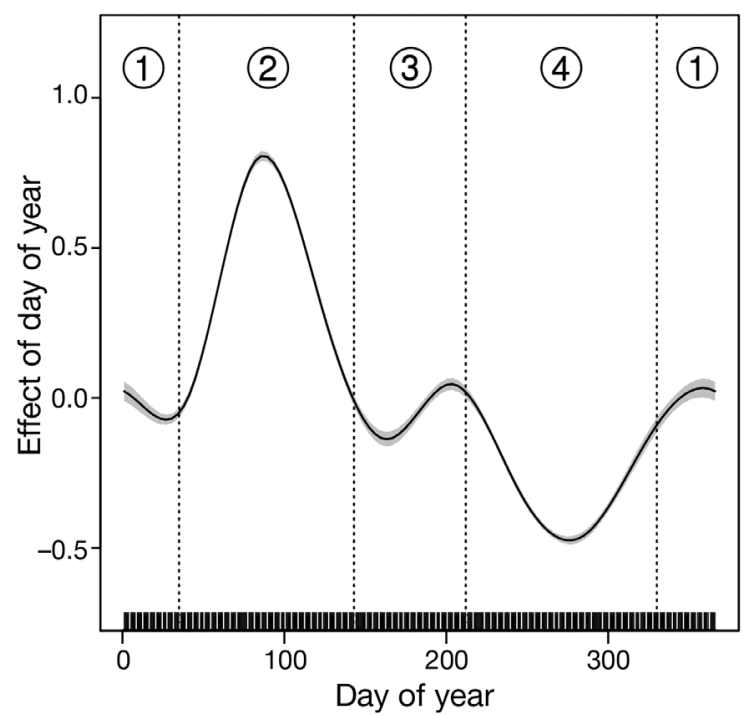

Fig. 3. Seasonal pattern of yellowfin sole Limanda aspera abundance (catch per unit effort, CPUE) as described by the effect of day of the year $(t)$ in Model 4 (see Table 1), with the shaded regions indicating $95 \%$ confidence interval. Vertical dotted lines separate 4 main periods at different fishing intensity: (1) December-January, (2) February-May, (3) June-July, (4) August-November. Ticks along $x$-axis: days on which measurements were made
To evaluate the relative effect of temperature and harvesting on the fish population, we calculated the expected variation in population size given by a variation in bottom temperature or catch. Our model suggested that an increase of $1^{\circ} \mathrm{C}$ of the average bottom temperature would produce a $7.3 \%$ increase in population size, while a $10 \%$ increase of the catches would result in a $11.9 \%$ decrease in the size of the population.

A second group of regression models, based on commercial trawl CPUE as response variable, was used for validation and for investigating seasonality of the harvesting process. Also in this case we found statistical support for modelling the effect of fisheries catch at small scale with a spatially variable formulation. A marked seasonal pattern characterized the commercial CPUE throughout the year (Fig. 3). The months from February to the first half of May were characterized by the highest CPUE values, while the period from August to November had the lowest values. Based on the commercial seasonality we identified 4 main fishing periods (Period 1: December-January; Period 2: February-May; Period 3: June-July; Period 4: August-November) that were used to build a model with a temporally variable spatial effect of

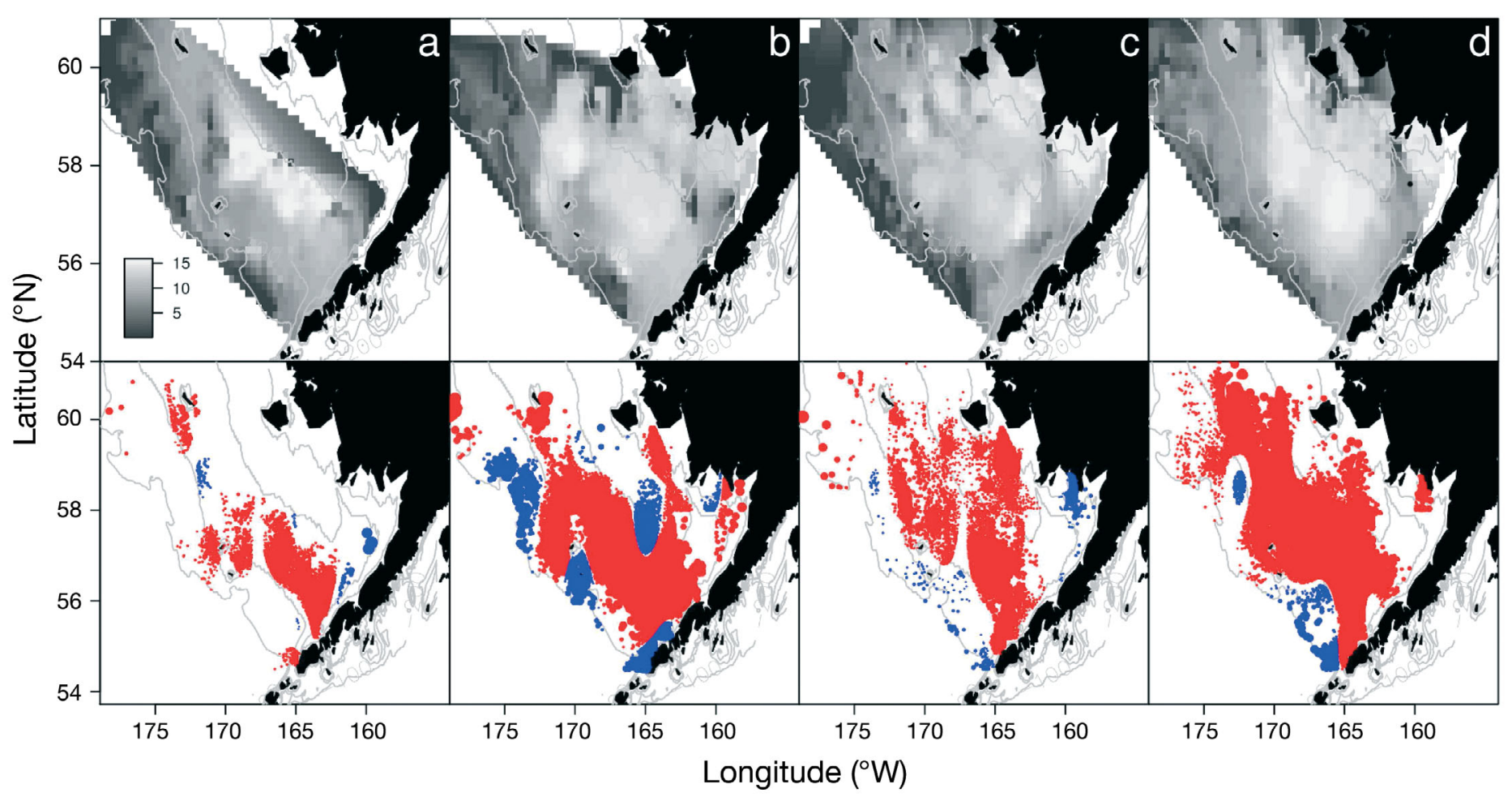

Fig. 4. Log-transformed weighted fisheries catch at small scale (kg) during the 4 main fishing seasons (upper plots): (a) December-January, (b) February-May, (c) June-July, (d) August-November. Effects of log-transformed fisheries catch at small scale on yellowfin sole Limanda aspera abundance (catch per unit effort, CPUE) during the same fishing seasons as estimated from Model 5 (lower plots). Red and blue bubbles indicate a positive and negative effect, respectively 
harvesting (Model 5, Table 1). In spite of its complexity this model resulted in the best GCV score (0.97 vs. 1.08 of Model 4, Table 1). The effect of fisheries catch was statistically significant across all 4 periods investigated (Periods 1-4: $F=32.0$ to 299.1, edf $=28.0$ to $29.0, \mathrm{p}<0.001$ ) and their inference validated for error spatial dependency with a mixed model (see Supplement 3). A similar overall positive association between the small-scale catch variable and the local fish density was estimated during the 4 fishing periods $\left(\alpha_{1-4}=0.14\right.$ to 0.15$)$, but substantial differences were found in the spatial structure of the effect among seasons (Fig. 4).

Period 1 was mainly dominated by a positive relationship between trawler CPUE and fisheries catch along part of the middle and outer shelf (Fig. 4). A few very small negative effects were found, such as those between the Pribilof Islands and St. Matthew Island. Period 2 was characterized by an extensive negative effect of commercial catches off the Alaska Peninsula and over the narrow shelf off Unimak Island, around the Pribilof Islands, along the shelfbreak between the Pribilof Islands and St. Matthew Island, in a large central area on the middle shelf centered at approximately $58^{\circ} \mathrm{N}, 165^{\circ} \mathrm{W}$, and in a very small area in the northern part of Bristol Bay (Fig. 4). During Period 3 negative effects of commercial catches were restricted to Bristol Bay, off the Alaskan Peninsula and from its tip to the Pribilof Islands along the limit of the outer shelf. The same deepest part of the shelf and an area between the Pribilof Islands and St. Matthew Island were characterized by a negative effect of catches on trawler CPUEs during Period 4. In contrast, the effect in Bristol Bay changed to positive (Fig. 4).

\section{DISCUSSION}

Species-environment interactions and exploitation processes both affect the spatial dynamics of yellowfin sole. Our regression approach was able to disentangle the competing and confounding effects of harvesting-induced local decline of fish abundance and positive associations between fisheries catches and their targeted resource.

Two spatiotemporal scales have been recognized in the present study on yellowfin sole, the regional or large scale of the entire eastern Bering Sea population and the local or small scale of the local aggregations. These scales are consistent with the ecological theory of scale domains recognizing a hierarchy of spatial and temporal scales (Goodwin \& Fahrig 1998), including (1) the global scale of the species range, (2) the regional scale comprising the distribution of populations, (3) the local scale comprising the spatial distribution of areas of aggregations within populations, and (4) the individual scale. The regional scale reflects the scale of the spatial pattern of the population mediated by the rate of successful movement between areas of aggregation (Goodwin \& Fahrig 1998); for yellowfin sole in the EBS, this would be expected to be influenced by some combination of the individual mobility, the distribution of the benthic resources (i.e. clams and polychaete worms), predation (i.e. halibut Hippoglossus stenolepis), and habiat selection (Bakkala 1981, Bartolino et al. 2011). In contrast, the local scale reflects the interaction between encounter probability within areas of aggregation (affecting competition and predation) and dispersal probability from areas of aggregation (Goodwin \& Fahrig 1998).

The effects of harvesting on yellowfin sole were not linearly related between the regional and local scales, which represent 2 distinct and separable aspects of the harvesting process. When the exploitation process of yellowfin sole was studied at the same spatiotemporal scale of the local aggregations of this population, we observed an increase in predictability of the spatial dynamics as detected by a minimum in the GCV of our model. These results are consistent with ecological theory indicating that predictability (i.e. ability to reproduce the observed data and the system dynamics) is likely to decrease from large to small scales (Levin 1987, Wiens 1989), but this decrease is expected to be non-monotonic (Goodwin \& Fahrig 1998). The multiscale analysis indicated that the negative effect of the harvesting process on local yellowfin sole densities was reduced by $40 \%$ after a period of approximately 3 mo. This result likely reflects the use of summer abundance from trawl surveys and the seasonal scale of spawning from late May until August (Wilderbuer et al. 1992). In fact the formation and subsequent dispersal of spawning aggregations from grounds in part outside the survey area to feeding grounds within the survey area would diminish the effect of fishery removals on abundances over a time period of about 3 mo. The movement from spawning areas to summer feeding areas likely accounts for the abrupt change in abundance shown in Fig. 2a for late July ( $t=200)$.

Similarly, the inshore spawning migration of yellowfin sole prior the groundfish survey may confound our interpretation of the small-scale effect of harvesting. In spring, adult yellowfin sole migrate across the shelf to nearshore spawning areas, mostly in the 


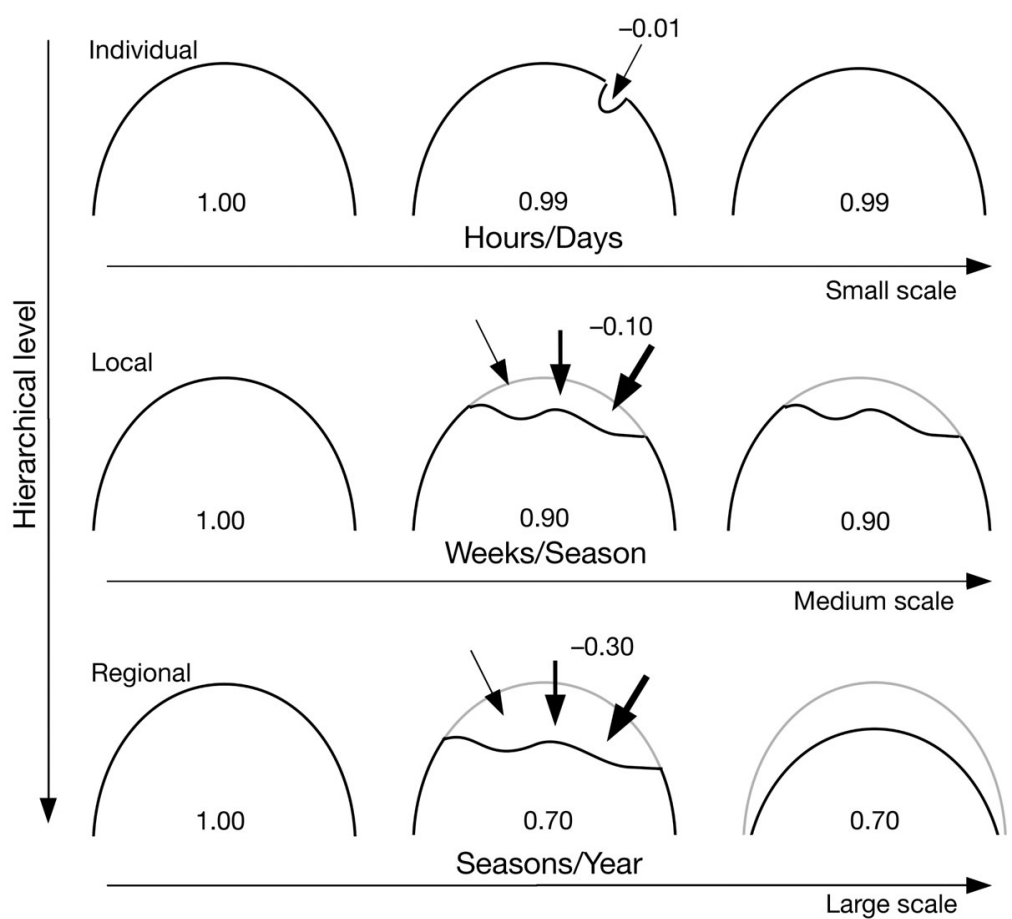

Fig. 5. Schematic of the distribution of a harvested population at different scales. From top to bottom, individual to regional hierarchical level, small to large scale; the $x$-axis is time. At each scale the curves represent a population before, during and after harvesting, and the area and number under the curves are proportional to the size of the population at each time. The size of the arrows is proportional to the intensity of exploitation, and the associated negative number represents the proportion of organisms harvested. Movements of organisms at the individual, local, and regional levels determine variations in the distribution of the population after harvesting at small, medium, and large scales, respectively not affect the validity of the framework proposed.

At the large scale, the negative relationship between fish density and the intensity of exploitation during the previous 12 mo and across the whole study area suggests not only that fisheries exploitation is able to produce detectable reduction of yellowfin sole abundance, but also that the effects of harvesting tend to be transferred throughout the area of distribution during the annual cycle. According to Levin \& Pacala (1997), we can interpret our findings in terms of activating and constraining processes. Local exploitation is a small-scale activating process that reduces local fish densities at the time of harvesting. The negative effect of harvesting is observed in those areas where the catches are higher, or where the rate of recolonization is low despite the low fishing pressure, such as in the marginal areas of the yellowfin sole distribution along the outer shelf. In contrast, the movement of fish and seasonal migration patterns are large-scale processes which constrain the effect of exploitation within a given area to specific boundaries. Thus, within the seasonal cycle fish from areas under different harvesting pressure are mixed, leading to a more uniform regional effect (Fig. 5).

shallow waters of Bristol Bay and off Nunivak Island (Nichol 1997) which are poorly sampled by the groundfish survey, with up to $20 \%$ of the adult fish biomass unavailable to the survey (D. G. Nichol pers. comm.) but potentially available for the fisheries. At a small scale, the sharp reduction in the weighting of the fishery catches prior to the survey upon fishery catches during the survey period is expected to mitigate the confounding effect of processes such as migration. Secondly, the central area between Kuskokwim Bay and Bristol Bay and the area off Unimak Island have been characterized by a negative effect of the fisheries catch and show elevated densities also at the time of the groundfish survey. This would suggest that even if densities have been reduced in these areas by some departure of spawning fish, they are still densely populated by yellowfin sole at the time of the survey. Thus, we cannot exclude that the negative effect of harvesting at small scale may have been overestimated due to the co-occurrence of spawning migration, but this would
Non-homogeneous spatial patterns of fishery effort have important implications for expected annual yield under equilibrium conditions (Ralston \& O'Farrell 2008), but the effect of spatial fishing patterns at intraannual temporal scales are less well recognized and have several management applications. Analyses of the interaction between intra-annual fishing patterns and distributions of environmental conditions would broaden our understanding of the effect of environmental variability upon fish distributions (Mueter \& Litzow 2008, Spencer 2008, Bartolino et al. 2011), as the impact of environmental variability upon a population may be expressed differently under different spatial patterns of fishing effort. A second application is economic analyses; because economic value of harvest is a function of location (through distance from port) and market price (which may vary seasonally), analyses of fishing patterns on intra-annual patterns of abundance could refine economic evaluation of spatial management measures. While EBS yellowfin sole are conservatively managed with annual harvests 
levels below recommended levels (Wilderbuer et al. 2008) and not considered a management concern, analyses at more refined spatial and temporal scales improve our understanding of the impacts of harvesting. The absence of linear correlation in the effects of harvesting across multiple spatial and temporal scales poses important limits on the extrapolation of the harvesting effects on natural populations over these scales, ultimately subordinating our understanding of the human impacts on natural populations to the identification of appropriate scales of investigation.

Our multiscale analysis of the exploitation process represents an efficient way to derive appropriate temporal and spatial scales of investigation, and the general framework can be readily applied to other marine species and systems to study not only human impacts, but also other scale-dependent processes, such as consumer-resource distribution, and species-environment interactions.

Acknowledgements. This work is funded by the North Pacific Research Board as part of project 709. We are grateful for partial support from the US National Science Foundation (NSF-0934617) for L.C. and K.S.C. We also thank L.C. Stige, E. Edeline, N. Bacheler, S. Kotwicki, S. Barbeaux, A. Belgrano and 3 anonymous reviewers for comments on the manuscript, and the scientists of the Alaska Fisheries Science Center (RACE division) who collected data in the eastern Bering Sea groundfish survey.

\section{LITERATURE CITED}

Bakkala RG (1981) Population characteristics and ecology of yellowfin sole. In: Wood DW, Calder JA (eds) The eastern Bering Sea shelf: oceanography and resources, Vol 1. US Dep Comm NOAA, Washington, DC, p 553-574

- Bartolino V, Ciannelli L, Bacheler NM, Chan KS (2011) Ontogenetic and sex-specific differences in densitydependent habitat selection of a marine fish population. Ecology 92:189-200

Bez N, Oliveira ED, Duhamel G (2006) Repetitive fishing, local depletion, and fishing efficiencies in the Kerguelen Islands fisheries. ICES J Mar Sci 63:532-542

Brooks TM, Mittermeier RA, Mittermeier CG, daFonseca GAB and others (2002) Habitat loss and extinction in the hotspots of biodiversity. Conserv Biol 16:909-923

> Charnov EL (1976) Optimal foraging: attack strategy of a mantid. Am Nat 110:141-151

> Cook RM, Hubbard SF (1977) Adaptive searching strategies in insect parasites. J Anim Ecol 46:115-125

Cushing DH (1982) Climate and fisheries. Academic Press, New York, NY

Eggleston DB, Johnson EG, Kellison GT, Nadeau DA (2003) Intense removal and non-saturating functional responses by recreational divers on spiny lobster Panulirus argus. Mar Ecol Prog Ser 257:197-207

Gardner RH, Kemp WM, Kennedy VS, Petersen JE (2001) Scaling relations in experimental ecology. Columbia University Press, New York, NY
Goodwin BJ, Fahrig L (1998) Spatial scaling and animal population dynamics. In: Peterson DL, Parker VT (eds) Ecological scale: theory ad applications. Columbia University Press, New York, NY, p 193-206

Hastie T, Tibshirani R (1993) Varying-coefficient models. J R Stat Soc B 55:757-796

Haury LR, McGowan JA, Wiebe PH (1978) Patterns and processes in the time-space scales of plankton distribution. In: Steele J (ed) Spatial pattern in plankton communities, NATO Conference Series Vol 4. Plenum Press, New York, NY, p 277-327

Hilborn R, Walters CJ (1992) Quantitative fisheries stock assessment: choice, dynamics and uncertainty. Chapman \& Hall, New York, NY

> Hutchings JA, Reynolds JD (2004) Marine fish population collapses: consequences for recovery and extinction risk. Bioscience 54:297-309

Jackson JBC, Kirby MX, Berger WH, Bjornda KA and others (2001) Historical overfishing and the recent collapse of the coastal ecosystem. Science 293:628-638

Lauth RR, Acuna E (2007) Results of the 2006 eastern Bering Sea continental shelf bottom trawl survey of ground fish and invertebrate resources. NOAA Tech Memo AFSC176, US Dep Comm NOAA, Seattle, WA

Levin SA (1987) Scale and predictability in ecological modeling. In: Vincent T, Cohen Y, Grantham W, Kirkwood G, Skowronski $\mathrm{J}$ (eds) Modeling and management of resources under uncertainty. Lecture Notes in Biomathematics, Vol 72. Springer, Heidelberg, p 2-8

Levin SA, Pacala SW (1997) Theories of simplification and scaling of spatially distributed processes. Princeton University Press, Princeton, NJ, p 271-296

> Maury O, Gascuel D (2001) 'Local overfishing' and fishing tactics: theoretical considerations and applied consequences in stock assessment studied with a numerical simulator of fisheries. Aquat Living Resour 14:203-210

> McConnaughey RA, Smith KR (2000) Associations between flatfish abundance and surficial sediments in the eastern Bering Sea. Can J Fish Aquat Sci 57:2410-2419

> Mueter FJ, Litzow MA (2008) Sea ice retreat alters the biogeography of the bering sea continental shelf. Ecol Appl 18:309-320

- Myers RA, Worm B (2003) Rapid worldwide depletion of predatory fish communities. Nature 423:280-283

> Myers RA, Worm B (2005) Extinction, survival or recovery of large predatory fishes. Philos Trans R Soc Lond B Biol Sci 360:13-20

Nichol DG (1997) Effects of geography and bathymetry in growth and maturity of yellowfin sole, Pleuronectes asper, in the eastern Bering Sea. Fish Bull 95:494-503

Nichol DG (1998) Annual and between-sex variability of yellowfin sole, Pleuronectes asper, spring-summer distributions in the eastern Bering Sea. Fish Bull 96:547-561

Ralston S, O'Farrell MR (2008) Spatial variation in fishing intensity and its effect on yield. Can J Fish Aquat Sci 65: 588-599

Reynolds JD, Dulvy NK, Goodwing NB, Hutchings JA (2005) Biology of extinction risk in marine fish. Proc R Soc Lond B Biol Sci 272:2337-2344

Richardson K, Heath MR, Pihl NJ (1986) Studies of a larval herring patch in the Buchan area. Dana 6:110

Ricklefs RE (1990) Scaling pattern and process in marine ecosystems. In: Sherman K, Grassle J, Gold B (eds) Large marine ecosystems: patterns, processes, and yields. American Association for the Advancement of Science, 
Washington, DC, p 169-178

Rijnsdorp AD, van Mourik Broekman PL, Visser EG (2000) Competitive interactions among beam trawlers exploiting local patches of flatfish in the north sea. ICES J Mar Sci 57:894-902

Schneider DC (1994) Quantitative ecology, spatial and temporal scaling. Academic Press, London

Smith KR, McConnaughey RA (1999) Surficial sediments of the eastern Bering Sea continental shelf: EBSSED database documentation. NOAA Tech Memo AFSC-104, US Dep Comm NOAA, Seattle, WA

Spencer P (2008) Density-independent and density-dependent factors affecting temporal changes in spatial distributions of eastern bering sea flatfish. Fish Oceanogr 17: 396-410

Stauffer G (2004) NOAA protocols for groundfish bottom trawl surveys of the nation's fishery resources. NOAA Tech Memo SPO-65, US Dep Comm NOAA, Seattle, WA

Steele JH (1991) Can ecological theory cross the land-sea boundary? J Theor Biol 153:425-436

Editorial responsibility: Jake Rice,

Ottawa, Canada
Steele JH, Henderson EW, Mangel M, Clark C (1994) Coupling between physical and biological scales. Philos Trans R Soc Lond B Biol Sci 343:5-9

Wiens JA (1989) Spatial scaling in ecology. Funct Ecol 3: 385-397

Wilderbuer TK, Walters GE, Bakkala RG (1992) Yellowfin sole, Pleuronectes asper, of the eastern Bering Sea: biological characteristics, history of exploitation, and management. Mar Fish Rev 54:118

Wilderbuer TK, Nichol DG, Ianelli J (2008) Yellowfin sole, North Pacific Fishery Management Council. In: NPFMC Bering Sea and Aleutian Islands. SAFE Rep, Anchorage, AK

Wood SN (2003) Thin plate regression splines. J R Stat Soc B 65:95-114

Wood SN (2004) Stable and efficient multiple smoothing parameter estimation for generalized additive models. J Am Stat Assoc 99: 673-686

Wood SN (2006) Generalized additive models: an introduction with R. Chapman \& Hall/CRC, Boca Raton, FL

Submitted: April 6, 2011; Accepted: September 30, 2011 Proofs received from author(s): December 16, 2011 